\title{
BMJ Open Physicians' patient base composition and mortality among people living with HIV who initiated antiretroviral therapy in a universal care setting
}

Beverly Allan, ${ }^{1}$ Kalysha Closson, ${ }^{1,2}$ Alexandra B Collins, ${ }^{2,3}$ Mia Kibel, ${ }^{1}$ Shenyi Pan, ${ }^{1}$ Zishan Cui, ${ }^{1}$ Taylor McLinden, ${ }^{1}$ Surita Parashar, ${ }^{1,2}$ Viviane Dias Lima, ${ }^{1,4}$ Jason Chia, ${ }^{1}$ Benita Yip, ${ }^{1}$ Rolando Barrios, ${ }^{1,4}$ Julio S G Montaner, ${ }^{1,4}$ Robert S Hogg ${ }^{1,2}$

To cite: Allan B, Closson K, Collins AB, et al. Physicians patient base composition and mortality among people living with HIV who initiated antiretroviral therapy in a universal care setting. BMJ Open 2019;9:e023957. doi:10.1136/ bmjopen-2018-023957

\section{- Prepublication history for} this paper is available online. To view these files, please visit the journal online (http://dx.doi. org/10.1136/bmjopen-2018023957).

Received 3 May 2018 Revised 9 October 2018 Accepted 23 November 2018

\section{Check for updates}

(c) Author(s) (or their employer(s)) 2019. Re-use permitted under CC BY-NC. No commercial re-use. See rights and permissions. Published by BMJ.

${ }^{1} \mathrm{BC}$ Centre for Excellence in HIV/AIDS, Vancouver, British Columbia, Canada

${ }^{2}$ Faculty of Health Sciences, Simon Fraser University, Burnaby, British Columbia, Canada

${ }^{3} \mathrm{BC}$ Centre on Substance Use, Vancouver, British Columbia, Canada

${ }^{4}$ Faculty of Medicine, University of British Columbia, Vancouver, British Columbia, Canada

Correspondence to

Kalysha Closson;

KClosson@cfenet.ubc.ca

\section{ABSTRACT}

Objectives To assess the impact of physicians' patient base composition on all-cause mortality among people living with HIV (PLHIV) who initiated highly active antiretroviral therapy (HAART) in British Columbia (BC), Canada.

Design Observational cohort study from 1 January 2000 to 31 December 2013.

Setting BC Centre for Excellence in HIV/AIDS' (BC-CfE) Drug Treatment Program, where HAART is available at no cost. Participants PLHIV aged $\geq 19$ who initiated HAART in $\mathrm{BC}$ in the HAART Observational Medical Evaluation and Research (HOMER) Study.

Outcome measures All-cause mortality as determined through monthly linkages to the BC Vital Statistics Agency. Statistical analysis We examined the relationships between patient characteristics, physicians' patient base composition, the location of the practice, and physicians' experience with PLHIV and all-cause mortality using unadjusted and adjusted Cox proportional hazards models. Results A total of 4445 PLHIV (median age $=42$, Q1, Q3 = 34-49; 80\% male) were eligible for our study. Patients were seen by 683 prescribing physicians with a median experience of 77 previously treated PLHIV in the past 2 years $(Q 1, Q 3=23-170)$. A multivariable Cox model indicated that the following factors were associated with all-cause mortality: age (aHR $=1.05$ per 1 -year increase, $95 \% \mathrm{Cl}=1.04$ to 1.06 ), year of HAART initiation (20042007: $\mathrm{aHR}=0.65,95 \% \mathrm{Cl}=0.53$ to $0.81,2008-2011$ : aHR $=0.46,95 \% \mathrm{Cl}=0.35$ to 0.61 , Ref: $2000-2003)$, CD4 cell count at baseline (aHR $=0.88$ per 100-unit increase in cells $/ \mathrm{mm}^{3}, 95 \% \mathrm{Cl}=0.82$ to 0.94 ), and $<95 \%$ adherence in first year on HAART (aHR $=2.28,95 \% \mathrm{Cl}=1.88$ to 2.76). In addition, physicians' patient base composition, specifically, the proportion of patients who have a history of injection drug use (aHR $=1.11$ per $10 \%$ increase in the proportion of patients, $95 \% \mathrm{Cl}=1.07$ to 1.15 ) or Indigenous ancestry (aHR $=1.07$ per $10 \%$ increase , $95 \% \mathrm{Cl}=1.03-1.11$ ) and being a patient of a physician who primarily serves individuals outside of the Vancouver Coastal Health Authority region (aHR $=1.22,95 \% \mathrm{Cl}=$ 1.01 to 1.47 ) were associated with mortality.

Conclusions Our findings suggest that physicians with a higher proportion of individuals who face potential barriers to care may need additional supports to decrease mortality
Strengths and limitations of this study

- Prospective data capturing almost all treatment-naïve individuals accessing antiretroviral therapy in the province of British Columbia, Canada.

- Longitudinal information on patients and physicians where antiretroviral therapy is universally available.

- Limited ability to capture many patients' mode of HIV acquisition.

- Potential for incomplete information due to reliance on routine clinical data collection.

among their patients. Future research is required to examine these relationships in other settings and to determine strategies that may mitigate the associations between the composition of physicians' patient bases and survival.

\section{INTRODUCTION}

Over the last two decades, research has shown that physicians' level of experience managing HIV infection can impact patients' HIV-specific health outcomes. ${ }^{12}$ Most notably, Kitahata et al ${ }^{1}$ was the first to demonstrate that physician experience was associated with better survival after the development of AIDS. After adjusting for the severity of illness and the year of HIV diagnosis, the study found that people living with HIV (PLHIV) cared for by physicians with the most clinical experience had approximately one-third lower risk of mortality than patients cared for by physicians with the least experience. ${ }^{2}$ Other studies have highlighted the potential impacts of physician experience, the model of care delivered, and the earlier adaptation of antiretroviral therapy on survival among PLHIV. ${ }^{3-6}$

Despite improved survival for PLHIV on highly active antiretroviral therapy (HAART) ${ }^{6-8}$ particular subgroups of PLHIV are still 


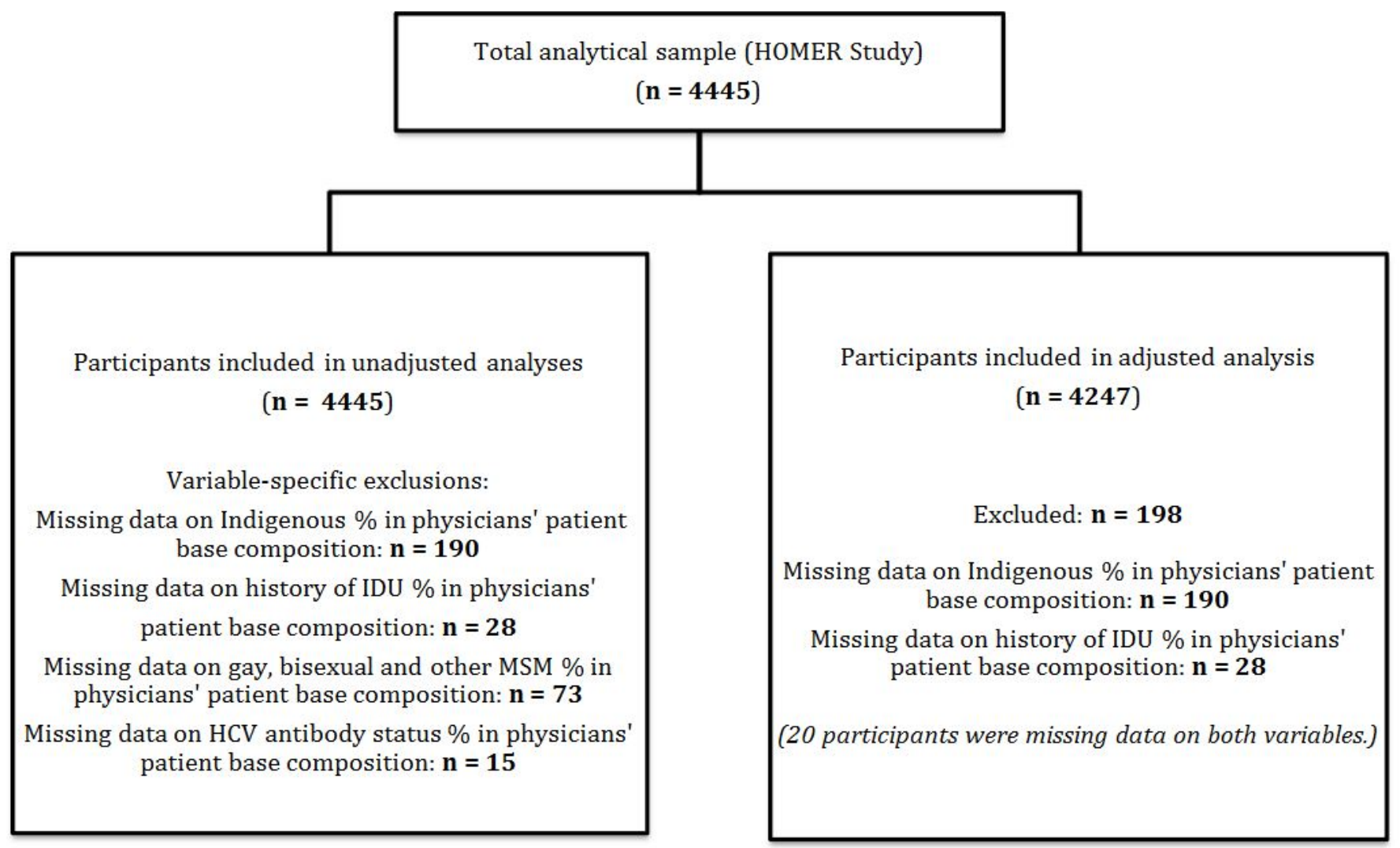

Figure 1 Flow diagram of participant inclusion in the statistical analyses. HCV, hepatitis C virus; HOMER, HAART Observational Medical Evaluation and Research Study; IDU, injection drug use; MSM, men who have sex with men.

disproportionately affected by higher mortality rates. ${ }^{59}{ }^{10} \mathrm{In}$ Canada, previous research has shown that PLHIV who have a history of injection drug use (IDU), who are of Indigenous ancestry, or who are women, have a lower life expectancy than their counterparts. ${ }^{510}$ This is despite universal health insurance and access to HAART, which has been available free of charge since 1996 to medically eligible PLHIV in British Columbia (BC), Canada, through the BC Centre for Excellence in HIV/AIDS' (BC-CfE) Drug Treatment Program (DTP).${ }^{11}$ A better understanding of the clinical contexts that potentially contribute to higher mortality among particular subgroups of PLHIV is thus integral to improving care for this population.

Taking this issue into consideration, our work sought to understand how physicians' patient base compositions and their experience impacts all-cause mortality of their patients living with HIV. We hypothesise that PLHIV attending physicians' clinics that provide care to a greater proportion of individuals from populations impacted by social and structural inequities have higher rates of mortality, independent of physician experience.

\section{METHODS}

\section{Study design and cohort description}

Medically eligible PLHIV in BC are automatically enrolled into the BC-CfE DTP upon a physician's prescription of HAART. This observational study is based on data from the HAART Observational Medical Evaluation and Research (HOMER) Study, which includes all BC-CfE DTP participants who were antiretroviral-naïve in BC prior to enrolment, aged 19 years or older at antiretroviral initiation, and whose first antiretroviral regimen included three or more active agents initiated on or after 1 August 1996. Eligible individuals were also required to have a CD4 cell count and plasma viral load measurement available within 6 months prior to HAART initiation. HOMER participants' demographic and clinical information, laboratory test results (including plasma viral load measurements and CD4 cell counts), HAART prescriptions, and other electronic health data are collected in the BC-CfE's electronic database. At enrolment into the DTP, participants are provided with information about data collection, use of their data in research, and the measures taken to ensure confidentiality. Cohort characteristics and DTP data collection and management procedures have been described in detail elsewhere. ${ }^{12}$ HOMER provides a comprehensive data source for investigating mortality, prognostic factors, and treatment responses among PLHIV across the province from the inception of HAART to a predetermined endpoint.

\section{Inclusion/exclusion criteria}

For this study, we included HOMER participants who initiated HAART in BC between 1 January 2000 and 31 
Table 1 Patient and prescribing physician characteristics at baseline $(n=4445)$.

\begin{tabular}{|c|c|c|}
\hline Variable & $\mathbf{N}$ or median & $\begin{array}{l}\text { \% or } \\
\text { (Q1-Q3) }\end{array}$ \\
\hline \multicolumn{3}{|l|}{ Participant characteristics } \\
\hline \multicolumn{3}{|l|}{ Sex } \\
\hline Male & 3565 & $80.2 \%$ \\
\hline Female & 880 & $19.8 \%$ \\
\hline Age: years & 42 & $34-49$ \\
\hline \multicolumn{3}{|l|}{ Year of HAART initiation } \\
\hline 2000-2003 & 907 & $20.4 \%$ \\
\hline 2004-2007 & 1212 & $27.3 \%$ \\
\hline 2008-2011 & 1657 & $37.3 \%$ \\
\hline 2012-2013 & 669 & $15.0 \%$ \\
\hline \multicolumn{3}{|l|}{ Adherence in first year on HAART } \\
\hline$\geq 95 \%$ & 3041 & $68.4 \%$ \\
\hline$<95 \%$ & 1404 & $31.6 \%$ \\
\hline $\begin{array}{l}\text { CD4 count at baseline (cells/ } \\
\mathrm{mm}^{3} \text { ) }\end{array}$ & 230 & $120-350$ \\
\hline \multicolumn{3}{|c|}{ Characteristics of participants' physicians } \\
\hline $\begin{array}{l}\text { Number of patients with HIV } \\
\text { seen by physician (past } 2 \text { years) }\end{array}$ & 77 & $23-170$ \\
\hline \multicolumn{3}{|c|}{ Proportion of patients in physicians' patient base* } \\
\hline Indigenous ethnicity & $14 \%$ & $9 \%-33 \%$ \\
\hline History of IDU & $41 \%$ & $19 \%-67 \%$ \\
\hline HCV antibody status (positive) & $41 \%$ & $24 \%-67 \%$ \\
\hline Gay, bisexual and other MSM & $47 \%$ & $12 \%-79 \%$ \\
\hline \multicolumn{3}{|c|}{ Majority health authority of physicians' patient base } \\
\hline $\begin{array}{l}\text { Vancouver Coastal Health } \\
\text { Authority }\end{array}$ & 2950 & $66.4 \%$ \\
\hline Other health authority & 1495 & $33.6 \%$ \\
\hline $\begin{array}{l}\text { Number of LHAs represented in } \\
\text { physician' patient base }\end{array}$ & 13 & $5-24$ \\
\hline
\end{tabular}

*See figure 1 for details on missing data related to physicians' patient base composition variables. Data for this variable are presented as a proportion because they represent the proportion of individuals in the physician's practice from select transmission groups.

HAART, highly active antiretroviral therapy; HCV, hepatitis C virus; IDU, injection drug use; LHA, local health area; MSM, men who have sex with men.

December 2013 with a known prescribing physician, and who were actively followed for at least 1 year.

\section{Patient and public involvement}

The HOMER Study is nested within the DTP, which works closely with community advisory boards in order to ensure that ongoing studies are relevant. Since the establishment of the cohort, many knowledge translation activities have been conducted in consultation with PLHIV to disseminate findings to people and communities affected by HIV.

\section{Outcome measure and explanatory variables}

The primary outcome of interest in this analysis is all-cause mortality, determined through monthly linkages to the BC Vital Statistics Agency. Independent variables obtained through the DTP included: age (years); sex (male vs female); year of HAART initiation (2000-2003 vs 2004-2007 vs 2008-2011 vs 2012-2013, to reflect changes in prescription guidelines for HAARTnaïve individuals); medication adherence (proportion of HAART prescription refills in the first year after prescription); baseline CD4 cell count at HAART initiation; the proportion of individuals in the physician's patient base from select transmission groups (eg, history of IDU; gay, bisexual and other men who have sex with men $[\mathrm{MSM}]$ ) and ethnicities (ie, Indigenous ancestry). In addition, the province of $\mathrm{BC}$ is divided into 89 local health areas (LHAs), which combine to form 5 aggregated health authorities that are used by the government in the planning of health services delivery. ${ }^{13}$ In this analysis, we counted the number of LHAs represented in each prescribing physician's patient base and whether patients in that practice mostly resided in the Vancouver Coastal Health Authority region (a higher proportion of urban residents) versus the other health authorities in BC (which have a comparatively lower proportion of urban residents). Finally, we included the variable physician experience, which was defined as the cumulative number of PLHIV whom the physician had previously monitored in the BC-CfE DTP in the 2 years prior to seeing each of the study participants.

\section{Statistical methods}

The unit of analysis in this study was the patient. Several patient characteristics and prescribing physician characteristics were compared using Pearson's $\chi^{2}$ tests for binary/categorical variables and Wilcoxon rank-sum tests for continuous variables. A trend analysis for all-cause mortality was conducted for select explanatory variables using Kaplan-Meier survival curves. We quantified the association between prescribing physician characteristics and time-to-death for their patients using Cox proportional hazards models; unadjusted and adjusted hazard ratios (HR) and 95\% confidence intervals (CI) are presented. Participants missing data on the characteristics of the prescribing physician were excluded from the analyses (see figure 1). Variables retained in the final multivariable model were selected using an exploratory model selection process based on Akaike Information Criterion (AIC) and type III p-values. Due to collinearity between hepatitis $\mathrm{C}$ virus (HCV) and IDU, the proportion of individuals in the physician's patient base who were HCV-positive was not included in the multivariable model. SAS V.9.3 (SAS Institute) was used to perform all statistical analyses. Ethical approval for this study was received from the University of British Columbia's Research Ethics Board (H05-50123). 

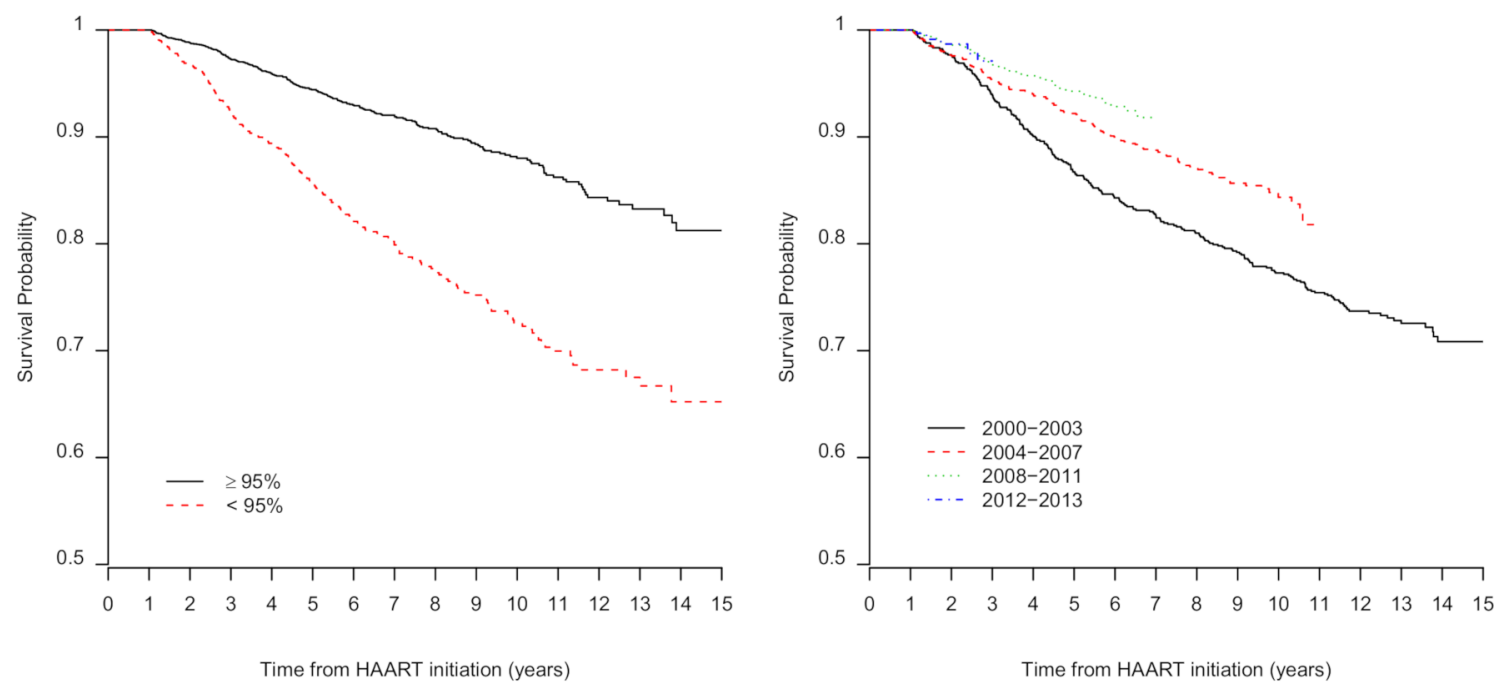

BY: Sex

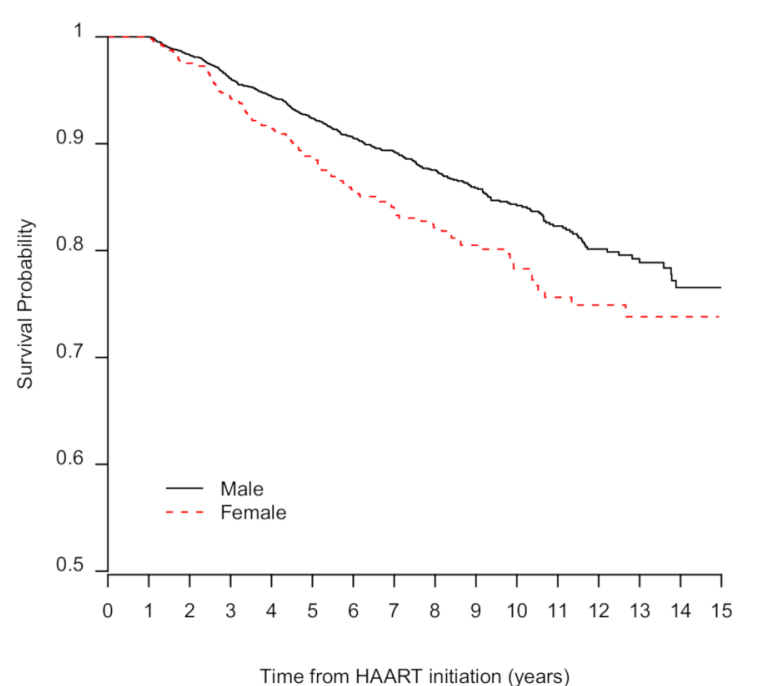

Figure 2 Kaplan-Meier survival curves by: adherence in the first year on HAART, year of HAART initiation, and sex.

\section{RESULTS}

A total of 4,445 PLHIV aged 19 years and over (median age $=42, \mathrm{Q} 1, \mathrm{Q} 3=34-49$ ) were enrolled in the study between 1 January 2000 and 31 December 2013, and were actively followed until 31 December 2014. Of these, $80.2 \%(\mathrm{n}=3,565)$ were male. The largest proportion of participants $(37.3 \%)$ initiated HAART between 2008 and $2011,68.4 \%(\mathrm{n}=3,041)$ were $\geq 95 \%$ adherent in first year on HAART , and $11.2 \%(\mathrm{n}=498)$ died during follow-up.

Table 1 describes select patient characteristics and their prescribing physician's characteristics at the time of HAART initiation. HOMER participants were seen by a total of 683 prescribing physicians. Participants' physicians had treated a median of $77(\mathrm{Q} 1, \mathrm{Q} 3=23-170)$ PLHIV on HAART in the 2 years prior to baseline. Overall, study participants attended physician practices where a median of $14 \%(\mathrm{Q} 1, \mathrm{Q} 3=9 \%-33 \%)$ of individuals were of Indigenous ancestry, 41\% (Q1, Q3 $=19 \%-67 \%)$ had a history of IDU, 41\% (Q1, Q3 = 24\%-67\%) had a positive HCV antibody status, and 47\% (Q1, Q3 $=12 \%-79 \%$ ) were gay, bisexual and other MSM. Missing data on physicians' patient base composition (proportion of patients with Indigenous ancestry, history of IDU, positive HCV antibody status, or gay, bisexual and other MSM) are described in figure 1. Compared with the rest of the patients, the individuals with missing values were more likely to be older, more likely to be from a health authority region other than Vancouver Coastal Health, more likely to be Indigenous (or with an unknown Indigenous status), and less likely to have a history of IDU (or have an unknown IDU status). Participants' physicians treated patients from a median of 13 LHAs (Q1, Q3 = 5-24), with the majority of LHAs within the Vancouver Coastal Health Authority (versus any other BC health authority).

Figure 2 presents descriptive Kaplan-Meier survival curves which show that females, those who started HAART 
Table 2 Unadjusted and adjusted Cox proportional hazard models quantifying the relationships between patient and prescribing physician characteristics and all-cause mortality

\begin{tabular}{|c|c|c|}
\hline & $n=4445$ & $n=4247$ \\
\hline Variable & $\begin{array}{l}\text { Unadjusted HR } \\
(95 \% \mathrm{Cl})\end{array}$ & $\begin{array}{l}\text { Adjusted HR } \\
(95 \% \mathrm{Cl})\end{array}$ \\
\hline \multicolumn{3}{|c|}{ Patient characteristics at baseline } \\
\hline \multicolumn{3}{|l|}{ Sex } \\
\hline Male & Ref & Not selected \\
\hline Female & $1.42(1.16-1.73)$ & Not selected \\
\hline Age* $^{*}$ & $1.03(1.02-1.04)$ & $1.05(1.04-1.06)$ \\
\hline \multicolumn{3}{|l|}{ Year of HAART initiation } \\
\hline $2000-2003$ & Ref & Ref \\
\hline 2004-2007 & $0.66(0.54-0.82)$ & $0.65(0.53-0.81)$ \\
\hline 2008-2011 & $0.45(0.35-0.58)$ & $0.46(0.35-0.61)$ \\
\hline $2012-2013$ & $0.46(0.24-0.88)$ & $0.62(0.32-1.21)$ \\
\hline $\begin{array}{l}\text { CD4 baseline (cells/ } \\
\mathrm{mm}^{3} \text { ) per } 100 \text { unit } \\
\text { increase }\end{array}$ & $0.82(0.77-0.88)$ & $0.88(0.82-0.94)$ \\
\hline \multicolumn{3}{|c|}{ Adherence in first year on HAART } \\
\hline$\geq 95 \%$ & Ref & Ref \\
\hline$<95 \%$ & $2.50(2.09-2.98)$ & $2.28(1.88-2.76)$ \\
\hline \multicolumn{3}{|c|}{ Characteristics of participant's physicians at baseline } \\
\hline $\begin{array}{l}\text { Number of patients } \\
\text { with HIV treated (past } \\
2 \text { years) per } 10 \text { patients }\end{array}$ & $0.98(0.97-0.99)$ & Not selected \\
\hline \multicolumn{3}{|c|}{$\begin{array}{l}\text { Proportion of patients in physicians' patient base, per } 10 \% \\
\text { increase } \dagger\end{array}$} \\
\hline Indigenous ethnicity & $1.15(1.12-1.19)$ & $1.07(1.03-1.11)$ \\
\hline History of IDU & $1.17(1.13-1.20)$ & $1.11(1.07-1.15)$ \\
\hline $\begin{array}{l}\text { HCV antibody } \\
\text { status (positive) }\end{array}$ & $1.18(1.14-1.21)$ & Not included \\
\hline $\begin{array}{l}\text { Gay, bisexual and } \\
\text { other MSM }\end{array}$ & $0.89(0.87-0.91)$ & Not selected \\
\hline $\begin{array}{l}\text { Number of LHAs } \\
\text { represented in } \\
\text { physician's patient } \\
\text { base* }^{*}\end{array}$ & $0.97(0.96-0.98)$ & Not selected \\
\hline \multicolumn{3}{|c|}{ Majority health authority of physician's patient base } \\
\hline $\begin{array}{l}\text { Vancouver Coastal } \\
\text { Health Authority }\end{array}$ & Ref & Ref \\
\hline Other health authority & $1.55(1.29-1.85)$ & $1.22(1.01-1.47)$ \\
\hline
\end{tabular}

${ }^{*}$ Per 1-unit increase.

†See figure 1 for details on missing data related to physicians' patient base composition variables.

HAART, highly active antiretroviral therapy; HCV, hepatitis C virus; IDU, injection drug use; LHA, local health area; MSM, men who have sex with men.

before 2004, and those with $<95 \%$ HAART adherence in their first year had a lower probability of survival over time $(\mathrm{p}<0.001)$.
Table 2 presents unadjusted and adjusted Cox models examining the relationships between participants' prescribing physician characteristics and all-cause mortality. In the unadjusted model, all patient factors and characteristics of the physicians' patient base composition were associated with mortality. A multivariable Cox model indicated that the following factors were associated with all-cause mortality: age (adjusted hazard ratio [aHR] $=1.05$ per 1 -year increase, $95 \% \mathrm{CI}=1.04$ to 1.06$)$, year of HAART initiation (2004-2007: $\mathrm{aHR}=0.65$, $95 \%$ CI $=0.53$ to $0.81,2008-2011:$ aHR $=0.46,95 \%$ CI $=0.35$ to 0.61, Ref: 2000-2003), CD4 count at baseline $\left(\mathrm{aHR}=0.88\right.$ per 100 -unit increase in cells $/ \mathrm{mm}^{3}, 95 \%$ $\mathrm{CI}=0.82$ to 0.94$)$, and $<95 \%$ adherence in first year on HAART $(\mathrm{aHR}=2.28,95 \% \mathrm{CI}=1.88$ to 2.76$)$. In addition, physicians' patient base composition, specifically, the proportion of patients who have a history of IDU (aHR $=1.11$ per $10 \%$ increase in the proportion of patients, $95 \% \mathrm{CI}=1.07$ to 1.15$)$ or Indigenous ancestry $(\mathrm{aHR}=$ 1.07 per $10 \%$ increase, $95 \% \mathrm{CI}=1.03$ to 1.11 ) and being a patient of a physician who primarily serves individuals outside of the Vancouver Coastal Health Authority region $(\mathrm{aHR}=1.22,95 \% \mathrm{CI}=1.01$ to 1.47$)$ were associated with mortality.

\section{DISCUSSION}

Our study demonstrates that after adjusting for patient characteristics including age, CD4 cell count, adherence in first year of HAART, and year of HAART initiation, several prescribing physicians' patient base composition characteristics remained associated with all-cause mortality. Specifically, we found that the following prescribing physicians' patient base composition characteristics were associated with mortality: the proportion of patients who have a history of IDU, the proportion of patients with Indigenous ancestry, and being the patient of a physician who primarilly serves individuals living outside of the Vancouver Coastal Health Authority region.

In unadjusted analyses, we found only a marginal association between physicians' experience treating patients with HIV and greater survival. While other studies have suggested that physician experience treating people with HIV does impact mortality, ${ }^{214}$ it is possible that we did not observe this association in our study because of other factors; age, year of HAART initiation, CD4 cell count, HAART adherence, and the location and composition of physicians' patient base may play a more substantial role in influencing a patients' survival in our setting.

Participants with prescribing physicians who provided care to a greater proportion of patients with a history of IDU were more likely to die during the follow-up period. Previous research has shown that PLHIV with a history of IDU are often faced with co-occurring mental health issues and other infections (eg, HCV),${ }^{15}$ as well as higher mortality rates. ${ }^{16}$ Moreover, PLHIV who use drugs face numerous intersecting barriers to HIV care (ie, stigma and socioeconomic and psychosocial disparities ${ }^{17-20}$ ) which 
may also be associated with mortality. ${ }^{21}$ Therefore, physicians who are treating a significant proportion of patients with a history of IDU may need additional support to reduce mortality in their patient base; integrated harm reduction approaches have been recommended as a public health strategy to improve patient engagement in care, which can reduce patient mortality. ${ }^{22}$

Regarding patients of physicians who serve a higher proportion of people with Indigenous ancestry, it is known that Indigenous people are disproportionately affected by HIV in BC, representing approximately $4 \%$ of the total BC population and $9 \%$ of those living with HIV. ${ }^{23}$ Literature has found that Indigenous people within Canada face adverse health outcomes due to histories of colonialism, poverty, housing instability, and systemic racism within the healthcare system. ${ }^{24-26}$ Physicians with a higher proportion of their patient base with Indigenous ancestry may benefit from targeted supports, and efforts could be made to increase physicians' cultural understandings of the social-structural factors exacerbating health disparities for many Indigenous communities in Canada. ${ }^{26}$

In 2013, the First Nations Health Authority was established in BC. This was done in an attempt to reclaim traditional healing practices and reform health service delivery for Indigenous people through the incorporation of traditional ways of health and healing that address the determinants of health. ${ }^{27}$ Physicians working within the First Nations Health Authority have increased opportunities for implementing culturally relevant and accessible HIV care, which may help to reduce mortality among populations impacted by HIV.

Notably, the Vancouver Coastal Health Authority region is predominantly urban and contains the city of Vancouver, as well as the BC-CfE. As a result, physicians serving a majority of patients in more rural areas of the province may be working in settings with fewer resources and servicing populations with co-occurring barriers to care. These barriers for PLHIV in rural settings can include high levels of community stigma and limited addiction, mental health, and HIV-specific services. ${ }^{28}$ Our results align with other studies during the same timeframe, which suggest that there may be a rural/urban gap in the quality of HIV care in BC, potentially related to poorer access to services and limited availability of specialised laboratory testing in remote locations. ${ }^{29}$ Efforts to increase targeted services to individuals in these other health authorities could be beneficial to reduce mortality among PLHIV.

The HOMER Study provides an invaluable resource for investigating the changing prognoses and treatment outcomes of PLHIV initiating HAART over time in BC. Unlike other cohorts, HOMER comprises an economically diverse population, as factors relating to financial barriers to treatment do not limit access to HAART in this setting. Similarly, as all participants are antiretroviral-naïve at baseline, previous antiretroviral use does not have the potential to introduce confounding bias. We were also able to capture all deaths that occurred in BC through regular linkages with BC's Vital Statistics Agency. Lastly, we limited losses to follow-up through the monitoring of individuals who discontinued treatment through laboratory tests and physician reporting. However, our work may be limited by the incomplete capture of data indicating the mode of HIV acquisition for many participants. Furthermore, we did not capture detailed data on physicians' level of knowledge and/or recent training on HIV care in BC.

In conclusion, we found that physicians' patient base composition, or more specifically, the proportion of patients who have a history of IDU, Indigenous ancestry, and being a patient of a physician who primarily serves individuals outside of the Vancouver Coastal Health Authority region were associated with all-cause mortality. This suggests that physicians with a higher proportion of patients who face potential barriers to care may need additional supports to decrease mortality among their patients. Future research is required to examine these relationships in other settings and to determine strategies that may mitigate the associations between the composition of physicians' patient bases and survival.

Acknowledgements We thank the patients who participated in our study and the staff from the British Columbia Centre for Excellence in HIV/AIDS, especially Benita Yip, for their assistance and commitment to maintain the HOMER dataset.

Contributors RSH and KC conceived of and designed the study. JC and BY conducted all data analysis. ZC performed all statistical analyses with guidance from VDL. KC, ABC, SP, and RSH contributed to the interpretation of the data. KC, $A B C$, and $\mathrm{RSH}$ drafted the manuscript. RB, JSGM, and RSH are responsible for the data and the interpretation of the data. BA, MK, TM, and SP were involved in the revisions of the manuscript. All authors reviewed the manuscript critically for important intellectual content and approved the final version submitted for publication.

Funding The BC-CfE Drug Treatment Program, the data source for this study, has received funding from the provincial government of British Columbia (PharmaCare).

Competing interests VDL is funded by a grant from the Canadian Institutes of Health Research (PJT-148595), by a Scholar Award from the Michael Smith Foundation for Health Research and a New Investigator Award from the Canadian Institutes of Health Research. JSGM is supported with grants paid to his institution by the British Columbia Ministry of Health and by the US National Institutes of Health (R01DA036307). He has also received limited unrestricted funding, paid to his institution, from Abbvie, Bristol-Myers Squibb, Gilead Sciences, Janssen, Merck and ViiV Healthcare. RSH has held grant funding in the past ten years from the US National Institutes of Health, the Canadian Institutes of Health Research, Health Canada, Merck, and the Social Sciences and Humanities Research Council of Canada.

Patient consent for publication Not required.

Provenance and peer review Not commissioned; externally peer reviewed.

Data sharing statement The HOMER Study is open to research collaborations with other scientists. However, owing to ethical considerations in the relation to relevant privacy legislation and research agreement, the analysis of the data is currently authorized to occur at the BC-CfE only. Researchers interested in collaborating should contact the Principal Investigator, RSH, at bobhogg@cfenet. ubc.ca with their expression of interest.

Open access This is an open access article distributed in accordance with the Creative Commons Attribution Non Commercial (CC BY-NC 4.0) license, which permits others to distribute, remix, adapt, build upon this work non-commercially, and license their derivative works on different terms, provided the original work is properly cited, appropriate credit is given, any changes made indicated, and the use is non-commercial. See: http:// creativecommons.org/licenses/by-nc/4.0/. 


\section{REFERENCES}

1. Kitahata MM, Koepsell TD, Deyo RA, et al. Physicians' experience with the acquired immunodeficiency syndrome as a factor in patients' survival. N Engl J Med 1996;334:701-7.

2. Kitahata MM, Van Rompaey SE, Dillingham PW, et al. Primary care delivery is associated with greater physician experience and improved survival among persons with AIDS. J Gen Intern Med 2003;18:95-103.

3. Kendall CE, Manuel DG, Younger J, et al. A population-based study evaluating family physicians' HIV experience and care of people living with HIV in Ontario. Ann Fam Med 2015;13:436-45.

4. Lima VD, Eyawo O, Ma H, et al. The impact of scaling-up combination antiretroviral therapy on patterns of mortality among HIV-positive persons in British Columbia, Canada. J Int AIDS Soc 2015;18:20261.

5. Samji H, Cescon A, Hogg RS, et al. Closing the gap: increases in life expectancy among treated HIV-positive individuals in the United States and Canada. PLoS One 2013;8:e81355.

6. Lima VD, Hogg RS, Harrigan PR, et al. Continued improvement in survival among HIV-infected individuals with newer forms of highly active antiretroviral therapy. AIDS 2007;21:685-92.

7. Hogg RS, Heath KV, Yip B, et al. Improved survival among HIVinfected individuals following initiation of antiretroviral therapy. JAMA 1998;279:450-4.

8. Palella FJ, Delaney KM, Moorman AC, et al. Declining morbidity and mortality among patients with advanced human immunodeficiency virus infection. HIV Outpatient Study Investigators. N Engl J Med 1998;338:853-60.

9. Antiretroviral Therapy Cohort Collaboration. Life expectancy of individuals on combination antiretroviral therapy in high-income countries: a collaborative analysis of 14 cohort studies. Lancet 2008;372:293-9.

10. Patterson S, Cescon A, Samji H, et al. Life expectancy of HIVpositive individuals on combination antiretroviral therapy in Canada. BMC Infect Dis 2015;15:274.

11. Montaner J. Therapeutic guidelines for antiretroviral (ARV) treatment of adult HIV infection: Vancouver British Columbia Centre for Excellence in HIV/AIDS, 2015.

12. Patterson S, Cescon A, Samji H, et al. Cohort Profile: HAART Observational Medical Evaluation and Research (HOMER) cohort. Int J Epidemiol 2015;44:58-67.

13. British Columbia (BC) Statistics. Regional health authorities. Secondary Regional health authorities. http://www2.gov.bc.ca/gov/ content/health/about-bc-s-health-care-system/partners/healthauthorities/regional-health-authorities

14. Mallinson RK, Rajabiun S, Coleman S. The provider role in client engagement in HIV care. AIDS Patient Care STDS 2007;21(Suppl 1):70-7.
15. Closson K, Osborne C, Smith DM, et al. Factors Associated with Mood Disorder Diagnosis Among a Population Based Cohort of Men and Women Living With and Without HIV in British Columbia Between 1998 and 2012. AIDS Behav 2017.

16. Braitstein P, Yip B, Montessori V, et al. Effect of serostatus for hepatitis $C$ virus on mortality among antiretrovirally naive HIV-positive patients. CMAJ 2005;173:160-4.

17. Werb D, Milloy MJ, Kerr T, et al. Injection drug use and HIV antiretroviral therapy discontinuation in a Canadian setting. AIDS Behav 2013;17:68-73.

18. O'Shaughnessy MV, Hogg RS, Strathdee SA, et al. Deadly public policy: what the future could hold for the HIV epidemic among injection drug users in Vancouver. Curr HIVIAIDS Rep 2012;9:394-400.

19. Wood E, Hogg RS, Lima VD, et al. Highly active antiretroviral therapy and survival in HIV-infected injection drug users. JAMA 2008;300:550-4.

20. Corneil TA, Kuyper LM, Shoveller J, et al. Unstable housing, associated risk behaviour, and increased risk for HIV infection among injection drug users. Health Place 2006;12:79-85.

21. Hayashi K, Dong H, Marshall BD, et al. Sex-based differences in rates, causes, and predictors of death among injection drug users in Vancouver, Canada. Am J Epidemiol 2016;183:544-52.

22. Kendall PRW. Integrated harm reduction approaches have been recommended as a public health strategy to improve patient engagement in care, which can reduce patient mortality: Provincial Health Officier. 2011.

23. Statistics Canada. Aboriginal peoples in Canada: first nations people, metis and inuit. Ottawa, Ontario Canada: Statistics Canada, 2016.

24. Browne AJ, Varcoe C, Lavoie J, et al. Enhancing health care equity with Indigenous populations: evidence-based strategies from an ethnographic study. BMC Health Serv Res 2016;16:544.

25. Shah BR, Gunraj N, Hux JE. Markers of access to and quality of primary care for aboriginal people in Ontario, Canada. Am J Public Health 2003;93:798-802.

26. Goodman A, Fleming K, Markwick N, et al. They treated me like crap and I know it was because I was Native: The healthcare experiences of Aboriginal peoples living in Vancouver's inner city. Soc Sci Med 2017;178:87-94.

27. First Nations Health Authority. Secondary First Nations Health Authority. 2017. http://www.fnha.ca/

28. Reif S, Golin CE, Smith SR. Barriers to accessing HIV/AIDS care in North Carolina: rural and urban differences. AIDS Care 2005;17:558-65.

29. MacKenzie LJ, Hull MW, Samji $\mathrm{H}$, et al. Is there a rural/urban gap in the quality of HIV care for treatment-naïve HIV-positive individuals initiating antiretroviral therapy in British Columbia? AIDS Care 2017;29:1218-26. 